\title{
APO DE ACESSIBILIDADE ESPACIAL EM ESCOLA DA REDE MUNICIPAL
}

\author{
SAVI, Aline Eyng \\ Universidade do Extremo Sul Catarinense, e-mail: arquiteta.alinesavi@gmail.com \\ ANTUNES, Elaine Guglielmi Pavei \\ Universidade do Extremo Sul Catarinense, e-mail: elainegpa@unesc.net \\ MEDEIROS, Pedro Luiz Kestering \\ Universidade do Extremo Sul Catarinense, e-mail: pkm@unesc.net \\ FABRE, Haron \\ Universidade do Extremo Sul Catarinense, e-mail: haron.fabre@unesc.net \\ MORETTI, Felype Dagostin \\ Universidade do Extremo Sul Catarinense, e-mail: fmoretti91@gmail.com
}

\begin{abstract}
RESUMO
A acessibilidade espacial escolar significa situar-se, orientar-se no espaço e compreender o que acontece, a fim de encontrar os diversos ambientes com suas diferentes atividades, sem precisar ser auxiliado. Considerando a inclusão de crianças com deficiência, este estudo tem como objetivo analisar as condições arquitetônicas e ambientais no espaço escolar, apresentando os resultados encontrados numa escola municipal do sul do estado de Santa Catarina. O trabalho faz parte de um projeto de extensão (em desenvolvimento), com a parceria do Observatório Social do município, numa investigação ampla das condições de acessibilidade nos edifícios escolares públicos. Os instrumentos metodológicos adotados para a Avaliação Pós-Ocupação baseiam-se na observação do usuário através do método: Passeio Acompanhado (DISCHINGER, 2000) e do pesquisador com a aplicação do check list do Manual de Acessibilidade (DISCHINGER; et al., 2009). Como resultado, apresentam-se princípios e diretrizes para o projeto arquitetônico de escolas acessíveis; e constata-se que as condições ambientais e arquitetônicas da escola apresentam obstáculos à acessibilidade, prejudicando a autonomia dos alunos com deficiência. Sabe-se que garantir o acesso espacial e o uso dos ambientes acredita-se ser uma condição básica para que se alcancem metas maiores de inclusão, vencendo as barreiras atitudinais.
\end{abstract}

Palavras-chave: Avaliação Pós-ocupação, Escola, Acessibilidade, Pessoa com Deficiência.

\begin{abstract}
The school space accessibility means to situate oneself, to orient oneself in the space and to understand what happens, in order to find the different environments with their different activities, without needing to be aided. Considering the inclusion of children with disabilities, this study aims to analyze the architectural and environmental conditions in the school space, presenting the results found in a municipal school in the southern state of Santa Catarina. The work is part of an extension project that is being developed in partnership with the Municipal Social Observatory, in a broad investigation of accessibility conditions in public buildings. The methodological tools used for Post-Occupancy Assessment are based on the observation of the user through the Accompanied Walk (DISCHINGER, 2000) and the researcher with the Accessibility Manual (DISCHINGER et al, 2009). As a result, principles and guidelines are presented for the architectural design of accessible schools. It is observed that the environmental and architectural conditions of the school present obstacles to accessibility, impairing the autonomy of students with disabilities.
\end{abstract}

SAVI, A. E.; ANTUNES, E. G. P.; MEDEIROS, P. L. K.; FABRE, H.; MORETTI, F. D. APO de acessibilidade espacial em escola da rede municipal. In: SIMPÓSIO BRASILEIRO DE QUALIDADE DO PROJETO NO AMBIENTE CONSTRUÍDO, 6., 2019, Uberlândia. Anais... Uberlândia: PPGAU/FAUeD/UFU, 2019. p. 988-997. DOI https://doi.org/10.14393/sbqp19091. 
It is known that in Brazilian society, there are important attitudinal barriers to be overcome with regard to inclusion. On the other hand, ensuring space access and the use of environments is believed to be a basic condition for achieving greater inclusion goals.

Keywords: Post-occupation Evaluation, School, Accessibility, Person with Disabilities.

\section{INTRODUÇÃO}

A qualidade arquitetônica do ambiente escolar influencia diretamente $O$ aprendizado pedagógico; e na situação de pessoas com deficiência, é um fator determinante para a inclusão, determinando sua autonomia. A acessibilidade espacial escolar significa bem mais do que apenas poder chegar ou entrar num lugar desejado. É, também, necessário que a pessoa possa situar-se, orientar-se no espaço e que compreenda o que acontece, a fim de encontrar os diversos lugares e ambientes com suas diferentes atividades, sem precisar ser auxiliado. Um lugar acessível deve permitir, através da maneira como está construído e das características de seu mobiliário, que todos possam participar das atividades existentes e que utilizem os espaços e equipamentos com igualdade $e$ independência na medida de suas possibilidades (DISCHINGER et al., 2009).

Na situação das escolas brasileiras, registra-se que os marcos legais históricos são motivos para o crescimento das matrículas de alunos com deficiência no ensino regular a cada ano. Ainda que lentamente, o Brasil avança mesmo com o quadro deficitário de infraestrutura das escolas. Há de se considerar, contudo, que o número da evasão escolar desses mesmos alunos é ainda expressivo, e entre os motivos está a dificuldade posterior, de inclusão escolar pela ignorância da acessibilidade espacial no projeto escolar (BRASIL, 2017).

Em consonância com ações de fortalecimento das políticas públicas na área de inclusão escolar no Brasil, o presente artigo, focado na importância do edifício para a atividade escolar, busca apresentar os instrumentos metodológicos usados para a Avaliação Pós-ocupação, com o intuito de avaliar a atual condição dos edifícios escolares da rede pública municipal de uma cidade no sul do estado de Santa Catarina. Para tal, com a parceira do Observatório Social do município, selecionou-se para apresentação, uma escola de ensino fundamental cujo critério para escolha foi o número elevado de alunos com deficiência. Registra-se que para garantir a privacidade dos dados, a escola não terá exposto seu nome e localização.

\section{REVISÃO TEÓRICA}

As questões de acessibilidade, quando focadas nos estabelecimentos de ensino, ampliam-se porque, além das barreiras espaciais, tratadas especificamente no artigo 24 do Decreto $n^{\circ} 5.296 / 2004$, incluem aspectos da inclusão escolar.

[...] os estabelecimentos de ensino de qualquer nível, etapa ou modalidade, públicos ou privados, proporcionarão condições de acesso e utilização de todos os seus ambientes ou compartimentos para pessoas com deficiência ou mobilidade reduzida, inclusive salas de aula, bibliotecas, auditórios, ginásios e instalações desportivas, laboratórios, áreas de lazer e sanitários (BRASIL, 2004). 
Essas demandas e exigências sociais e legais trazem a necessidade de estudar e organizar as informações espaciais sobre as edificações, seus ambientes, mobiliários e equipamentos, a fim de proporcionar condições adequadas de acessibilidade e inclusão espacial de pessoas com deficiência (ABNT, 2015). Além disso, elas também trazem novos requisitos ao processo de projeto, uma vez que a qualidade dos ambientes da escola e a participação da comunidade escolar estão fortemente inseridas na perspectiva da escola inclusiva.

Segundo o Manual de Acessibilidade Compactado (DISCHINGER; BINS ELY; PIARDI, 2012), acessibilidade espacial se refere a muito mais que apenas atingir um local desejado. Diz respeito à necessidade que o local permita ao usuário compreender sua função, organização e relações espaciais, assim como participar integralmente de todas as atividades que ali existem. Tais ações devem ser realizadas com independência, segurança e conforto.

Para que isso ocorra, é necessário que o ambiente atenda todas as necessidades do usuário, nas suas mais diversas naturezas. Deve ser possível que qualquer pessoa obtenha informações sobre o ambiente, suas atividades existentes e localizações; quais os caminhos possíveis para atingi-las, e quais os meios de deslocamento disponíveis. Ao longo de todo percurso, deve ser possível se deslocar com segurança e conforto; e ao atingir o local desejado, o usuário deve poder participar das atividades-fim, utilizando os espaços e equipamentos com igualdade e independência.

Para orientar as ações de avaliação e fiscalização do ambiente público, Dischinger, Bins Ely e Piardi (2012), classificam em quatro categorias os componentes da acessibilidade espacial: a orientação espacial, comunicação, deslocamento e uso. Cada uma dessas categorias apresenta um conjunto de diretrizes que devem ser cumpridas a fim garantir a acessibilidade em edifícios públicos e minimizar as restrições aos usuários. Vale ressaltar que acessibilidade espacial depende do cumprimento de tais diretrizes como um todo, e a falha em cumprir apenas uma delas pode comprometer todos os demais itens.

A orientação espacial diz respeito às características que fazem o usuário reconhecer a identidade e as funções do espaço, assim como definir estratégias para seu deslocamento e uso. Vários processos interligados ocorrem para que o indivíduo possa se orientar no espaço. Primeiro, é necessário obter informações do ambiente por meio da percepção. Depois, essas informações devem ser processadas cognitivamente, permitindo a elaboração mental de representações e definir ações. Sendo assim, as condições de orientação dependem tanto de elementos arquitetônicos e informativos do local (como placas, cores, sinais, letreiros e etc.) como da condição do indivíduo de processar essas informações, tomar decisões e agir (BINS ELY; BRANDÃO; BERTOLETTI, 2010).

A comunicação diz respeito à possibilidade da troca de informações interpessoais, ou troca de informações entre o usuário e o equipamento utilizado. Deve ser possível, por exemplo, que um estrangeiro disponha de tradutor caso tenha que responder uma acusação à um juizado, ou que um aluno cego que frequente o ensino regular tenha acesso à livros em braile, assim como professores pedagogicamente preparados para atender a esse tipo de necessidade especial. "A informação deve ser acessível a todos" 
(DISCHINGER; BINS ELY; PIARDI, 2012, p. 30). Avaliar as condições de comunicação é especialmente importante para garantir e melhorar a independência de pessoas com problemas auditivos, deficiência cognitiva ou problemas na fala.

As condições de deslocamento em ambientes públicos dizem respeito a possibilidade de qualquer pessoa poder movimentar-se de maneira independente pelas circulações horizontais e verticais, livre de interrupções e/ou barreiras, com seu conforto e segurança assegurados, a fim de chegar ao local desejado. No caso de haver desníveis, devem existir rampas ou rotas alternativas de acesso. As superfícies de revestimento devem ser planas e de material aderente, a fim de evitar acidentes (ABATE, 2011).

As condições de uso dos espaços e dos equipamentos referem-se à possibilidade de realização das atividades por todas as pessoas. Os equipamentos em salas de aula, banheiros e demais ambientes públicos devem estar adequados às normas de acessibilidade, permitindo que os usuários portadores de deficiências possam utilizá-los de maneira segura e confortável. Por exemplo, em um banheiro, além das pias e botões estarem dispostas de maneira acessível, é necessário também que o sanitário possua barras de apoio, dimensões e altura adequadas para permitir a manobra e a transferência da cadeira de rodas (DISCHINGER; BINS ELY; PIARDI, 2012).

Sendo assim, pode-se concluir que acessibilidade espacial é muito mais do que permitir que as pessoas cheguem a um determinado local. O ambiente deve permitir, através da compreensão das diferentes necessidades, que o usuário navegue pelo local de forma segura e confortável, e possa utilizar dos equipamentos e fazer parte das atividades-fim. Através dos quatro componentes explicados anteriormente, pode-se fazer um diagnóstico preciso dos problemas espaciais de determinado espaço, e assim melhorar a qualidade do uso de todos os usuários, independentemente de suas capacidades e habilidades.

A percepção dessa experiência faz com que o indivíduo confira significado ao mundo social e neste sentido, tem um papel importante no trabalho educativo, especialmente na inclusão das crianças com deficiência. A tarefa de construir e reconstruir o conhecimento e as experiências apreendidas com o espaço escolar, faz os alunos deve conferiram novos sentidos e novos significados ao mundo e a sua própria experiência nele. Segundo Rocha (2002), uma educação interessada no crescimento do indivíduo deve privilegiar a percepção como um conhecimento da realidade, um conhecimento situado porque a percepção também está vinculada aos valores desenvolvidos e estimulados pelas diferenças do ser humano.

Logo, para poder realizar as alterações necessárias a fim de garantir aos usuários uma certa qualidade em acessibilidade espacial, é necessário compreender os diferentes tipos de deficiência e suas necessidades para a realização de atividades. Depois, deve-se saber identificar quais são as barreiras espaciais que impedem a realização de tais atividades.

\section{APO E OS INSTRUMENTOS UTILIZADOS}

A pesquisa tem abordagem qualitativa, exploratória e multimétodos, e se enquadra na linha de avaliação pós-ocupação (APO). Centra-se na 
compreensão da relação entre os usuários (estudantes) e o ambiente escolar (ABATE et al., 2014).

Tal definição justifica a opção dessa metodologia enquanto forma de abordagem do problema da acessibilidade espacial nos edifícios escolares, permitindo a visão através do pesquisador e do usuário. Ante as possibilidades que se apresentam pela metodologia, os instrumentos relacionados abordam os fatores técnicos e funcionais do edifício através do instrumento: Manual de Acessibilidade Espacial para Escolas: o direito à escola acessível (DISCHINGER et al., 2009) e comportamentais pelo: Passeio Acompanhado (DISCHINGER, 2000).

O Manual identifica as dificuldades encontradas por alunos com deficiência no uso dos espaços e equipamentos escolares. Sua aplicação relaciona a norma brasileira de acessibilidade aos ambientes e aspectos ergonômicos, declarando-os aptos ou não a receber qualquer aluno, considerando o espaço físico e equipamentos que devem estar preparados para garantir acessibilidade. Registra-se que o Manual apresenta condições previstas pela Associação Brasileira de Normas Técnicas na NBR 9050 de 2004. Como esta foi revisada em 2015, houve a readequação do Manual pela equipe de trabalho. Após essa atividade, a aplicação ocorreu. Vale salientar que apenas duas pessoas são necessárias para a aplicação do Manual. Sendo importante conferir as medidas com trena e registrar visualmente todos os itens fiscalizados, pois fotos e desenhos são imprescindíveis para compreensão do espaço edificado e para ilustração das irregularidades, auxiliando na construção do relatório. O Manual foi aplicado em todos os ambientes internos e externos da escola de estudo de caso. O resultado foram as tabelas preenchidas e que posteriormente, auxiliaram no apontamento das maiores deficiências da escola no que tange as condições de acessibilidade espacial.

A fim de aprofundar as informações acerca da acessibilidade nos passeios públicos sob a ótica dos maiores prejudicados no que tange a falta de acessibilidade, foi utilizado o método do Passeio Acompanhado (DISCHINGER, 2000), que busca uma percepção do usuário com deficiência em situações reais de uso dos espaços. Este método qualitativo consiste em escolher entrevistados e determinar um percurso relevante ao estudo, avaliando suas condições de uso através da percepção do usuário com deficiência em situações reais. Os percursos devem possuir um ponto de partida e objetivos a alcançar. No decorrer do passeio, o pesquisador deve apenas acompanhar, e simultaneamente fazer anotações sobre as impressões do entrevistado no decorrer do percurso, transcrevendo ou gravando falas importantes e fotografando situações relevantes, mas não conduzir ou ajudar o entrevistado na realização das atividades, a exceção de situações de perigo iminente.

Na escola, o percurso escolhido teve como ponto de início a parada de ônibus (visto que a maioria dos alunos se utiliza de transporte público para acesso), devendo acessar o pátio coberto, o banheiro até a sala de aula. 0 participante da pesquisa possuía paraplegia e fazia uso de cadeira de rodas, registra-se que o trabalho se encontra em andamento. Esse artigo optou apresenta a pesquisa com a cadeirante, em razão desse ter maiores limitações quanto ao uso e apropriação espacial, do que os demais selecionados para a pesquisa, que foram: crianças com deficiência cognitivas e criança com amputação parcial de membro superior. O resultado da pesquisa com cada um dos investigados tem servido para reforçar as leituras 
do Manual, apontando os ambientes mais críticos da escola no que tange a acessibilidade espacial.

\section{ALGUNS DOS RESULTADOS ENCONTRADOS}

A Escola Municipal de Educação Básica foi fundada em 1986. É uma unidade educacional que atende ao ensino infantil e fundamental. Está localizada em rede urbana de um município, ao sul da capital do estado de Santa Catarina. É um colégio que se propõe o "compromisso de melhoria na qualidade de vida e a construção de sua autonomia", segundo a Secretária de Educação. A escola possui 29 funcionários (entre professores e colaboradores) e 230 alunos. Destes, treze são classificados para educação especial, segundo dados do último Censo Escolar (BRASIL, 2017), sendo um cadeirante, duas crianças com deficiência cognitivas e uma com amputação parcial de membro superior. Sobre a infraestrutura, o Censo destacado que não há dependências e sanitários acessíveis às pessoas com deficiência (BRASIL, 2017).

A Escola funciona em prédio próprio dividido blocos, que abrigam diversas funções (Figura 01). A estrutura passou por diferentes ampliações, refletida na tipologia dos blocos. A unidade dessa arquitetura ocorre pela materialidade de acabamento, com a pintura de cores uniformes nos blocos. A união na implantação, acontece pelos caminhos/fluxos entre os corredores e passarelas cobertas. O terreno com topografia acidentada permite que a Escola possua implantação em platôs, com pátio externo interligado por rampas e escadas. A parte da frente possui parque infantil para crianças do ensino fundamental. Nos fundos do lote, há um ginásio poliesportivo coberto.

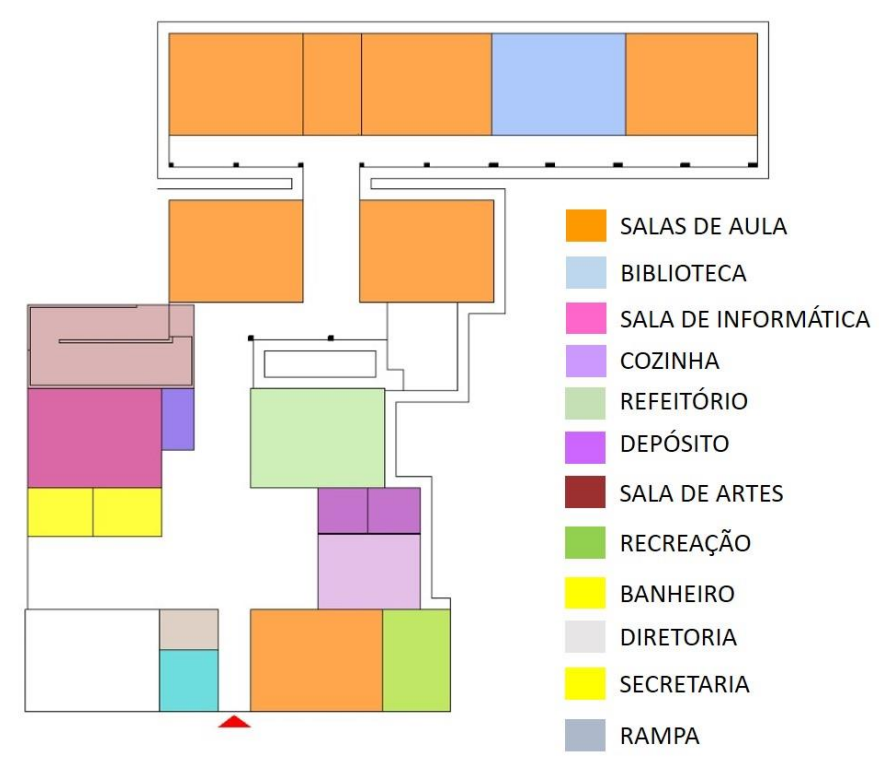

Figura 01 - Setorização por cores da escola Fonte: Elaborado pelos autores

Para organizar e apresentar nesse artigo as informações adquiridas, foi criado um Quadro Síntese (Quadro 01), onde são identificados os principais problemas de acessibilidade espacial encontrados. Estes estão organizados em três colunas: (01) Ambientes, ilustrado por uma imagem; (02) Avaliação, apresenta a situação observada, descrevendo os principais aspectos 
negativos do ambiente; e (03) Recomendação, onde são sugeridas soluções para as questões negativas apontadas anteriormente.

Quadro 01 - Síntese da avaliação de acessibilidade espacial

\begin{tabular}{|c|c|c|}
\hline Ambientes e Elementos & Avaliação & Recomendação \\
\hline & $\begin{array}{l}\text { Rua sem calçamento e } \\
\text { passeio público, o que } \\
\text { dificulta a chegada de } \\
\text { pessoas com deficiência } \\
\text { motora e/ou cadeira de } \\
\text { rodas. }\end{array}$ & $\begin{array}{l}\text { Existência de área de } \\
\text { embarque e desembarque } \\
\text { próxima ao portão. Calçada } \\
\text { com previsão de desnível } \\
\text { para acesso de cadeira de } \\
\text { rodas e piso tátil para } \\
\text { deficientes visuais. }\end{array}$ \\
\hline Porte & $\begin{array}{l}\text { Caminho muito amplo, sem } \\
\text { limites definidos, não possui } \\
\text { piso tátil direcional para guiar } \\
\text { pessoas com deficiência } \\
\text { visual até a porta da escola, e } \\
\text { o piso utilizado é } \\
\text { escorregadio. }\end{array}$ & $\begin{array}{l}\text { A porta de entrada deve ser } \\
\text { visível desde o portão, sendo } \\
\text { facilmente identificada por } \\
\text { uma marquise em cor forte, } \\
\text { por exemplo. O caminho de } \\
\text { pedestres deve ser } \\
\text { pavimentado, com piso } \\
\text { regular, antiderrapante e } \\
\text { não-ofuscante. }\end{array}$ \\
\hline Rece & $\begin{array}{l}\text { Recepção não identificável a } \\
\text { partir da entrada da escola. } \\
\text { Ambiente muito amplo, sem } \\
\text { piso tátil direcional para guiar } \\
\text { pessoas com deficiência } \\
\text { visual. Ambiente interno sem } \\
\text { contraste de cor entre piso e } \\
\text { paredes, o que dificulta na } \\
\text { percepção para pessoas com } \\
\text { baixa visão. }\end{array}$ & $\begin{array}{l}\text { No ambiente interno, o } \\
\text { balcão de atendimento deve } \\
\text { ser sempre visível a partir da } \\
\text { entrada e possuir duas alturas. } \\
\text { O piso tátil direcional deve } \\
\text { conduzir até os principais } \\
\text { ambientes ou ao mapa tátil. } \\
\text { As circulações devem estar } \\
\text { livres de obstáculos e existir } \\
\text { espaços de espera para } \\
\text { pessoas em cadeira de rodas. }\end{array}$ \\
\hline Cor & $\begin{array}{l}\text { Não há contraste de cor entre } \\
\text { piso, parede e portas que } \\
\text { facilite a orientação de } \\
\text { pessoas com baixa visão. Os } \\
\text { corredores são muito amplos, } \\
\text { sem piso tátil direcional para } \\
\text { guiar pessoas com deficiência } \\
\text { visual. }\end{array}$ & $\begin{array}{l}\text { O rodapé deveria ser largo e } \\
\text { em cor contrastante com o } \\
\text { piso antiderrapante, regular e } \\
\text { em boas condições. }\end{array}$ \\
\hline Rampa. & $\begin{array}{l}\text { Não existe piso tátil de alerta } \\
\text { no início e no final da rampa. } \\
\text { Não há corrimãos nos dois } \\
\text { lados. Há diferentes } \\
\text { inclinações na rampa. }\end{array}$ & $\begin{array}{l}\text { As escadas e rampas devem } \\
\text { possuir piso tátil de alerta no } \\
\text { seu início e fim. Os corrimãos } \\
\text { devem ser contínuos, } \\
\text { confortáveis e dos dois lados } \\
\text { das escadas e rampas, além } \\
\text { de estarem instalados em } \\
\text { duas alturas. }\end{array}$ \\
\hline
\end{tabular}




\begin{tabular}{|c|c|c|}
\hline$+. .5=$ & $\begin{array}{l}\text { Falta contraste de cor entre } \\
\text { piso, parede e móveis. } \\
\text { Carteiras com dimensões que } \\
\text { não permitem a aproximação } \\
\text { de cadeira de rodas. Corredor } \\
\text { muito estreito entre as } \\
\text { carteiras para a passagem de } \\
\text { cadeira de rodas. Espaço } \\
\text { muito estreito entre o quadro- } \\
\text { negro e as carteiras para a } \\
\text { circulação e manobra de } \\
\text { cadeira de rodas. }\end{array}$ & $\begin{array}{l}\text { O piso, as paredes e os } \\
\text { móveis devem possuir cores } \\
\text { contrastantes. Deve existir } \\
\text { mesa adequada para a } \\
\text { aproximação e uso de } \\
\text { crianças em cadeira de } \\
\text { rodas, bem como espaço no } \\
\text { corredor para passagem. }\end{array}$ \\
\hline and & $\begin{array}{l}\text { Mesas com altura } \\
\text { inadequada, que impedem a } \\
\text { aproximação de pessoas em } \\
\text { cadeira de rodas. Prateleiras } \\
\text { muito altas para que pessoas } \\
\text { em cadeira de rodas ou } \\
\text { crianças menores alcancem } \\
\text { os livros. }\end{array}$ & $\begin{array}{l}\text { As mesas e as prateleiras não } \\
\text { devem possuir obstáculos } \\
\text { para aproximação de uma } \\
\text { cadeira de rodas e terem } \\
\text { altura adequada ao uso de } \\
\text { pessoas com baixa estatura. }\end{array}$ \\
\hline & $\begin{array}{l}\text { Não existem sanitários } \\
\text { acessíveis na escola. }\end{array}$ & $\begin{array}{l}\text { Considerar construção e } \\
\text { observar a NBR 9050/2015 } \\
\text { para elaboração e execução } \\
\text { do projeto. }\end{array}$ \\
\hline & & \\
\hline Refe & $\begin{array}{l}\text { Não há contraste de cor entre } \\
\text { piso, parede e móveis. O } \\
\text { mobiliário não possui } \\
\text { dimensões que possibilitem o } \\
\text { uso de diversos tipos de } \\
\text { usuários, como crianças } \\
\text { pequenas, pessoas obesas ou } \\
\text { cadeirantes. }\end{array}$ & $\begin{array}{l}\text { O piso, as paredes e os } \\
\text { móveis devem possuir cores } \\
\text { contrastantes. As mesas e } \\
\text { cadeiras devem permitir uso } \\
\text { confortável para pessoas } \\
\text { com diferentes idades. Os } \\
\text { corredores entre as mesas } \\
\text { devem ser largos e permitirem } \\
\text { a circulação e a manobra de } \\
\text { cadeira de rodas. }\end{array}$ \\
\hline Ginásio de esportes. & $\begin{array}{l}\text { Não há rota acessível que } \\
\text { permita às pessoas com } \\
\text { mobilidade reduzida } \\
\text { chegarem à quadra, aos } \\
\text { bancos/arquibancadas ou } \\
\text { sanitários e vestiários. }\end{array}$ & $\begin{array}{l}\text { No caminho entre a escola e } \\
\text { a quadra deve ser previsto } \\
\text { alargamento e piso } \\
\text { pavimentado em cor } \\
\text { contrastante com a grama, } \\
\text { além do piso guia e alerta. } \\
\text { Deve ser previsto espaços } \\
\text { destinados à permanência de } \\
\text { pessoas em cadeira de rodas } \\
\text { nas arquibancadas. }\end{array}$ \\
\hline Pátio externo. & $\begin{array}{l}\text { A escola não possui pátio com } \\
\text { espaços amplos para } \\
\text { brincadeiras, nem mobiliário } \\
\text { adequado. }\end{array}$ & $\begin{array}{l}\text { O pátio deveria possuir áreas } \\
\text { bem definidas para as } \\
\text { diferentes atividades, como } \\
\text { locais pavimentados, } \\
\text { gramados, áreas para brincar } \\
\text { e estar, prevendo o acesso } \\
\text { também para pessoas com } \\
\text { deficiência. }\end{array}$ \\
\hline
\end{tabular}

Fonte: Elaborado pelos autores 
Estes são apenas alguns dos diversos aspectos negativos acerca da acessibilidade espacial encontrados na escola. A avaliação deixou evidente a falta de coerência entre a legislação e o que realmente acontece na prática. O espaço físico não está adequado para receber alunos com diferentes deficiências. A falta de acessibilidade de seus espaços e o modo como estes estão organizados faz com que os alunos com deficiências se tornem dependentes da ajuda alheia, apesar de possuírem legalmente o direito à autonomia, conforto e segurança. A atual situação torna-se incoerente com o princípio proposto pela Secretaria de Educação: "de construção de sua autonomia". Registra-se que apesar das constantes reformas e ampliações ocorridas, que incluíram medidas para atender a um projeto universal, os ambientes acessíveis são, sobretudo, um conjunto de medidas cuja análise dos usuários é fundamental, e não a adoção de medidas parciais, contemplando apenas algumas restrições.

\section{CONSIDERAÇÕES FINAIS}

O tema da acessibilidade em espaços públicos é de extrema importância e urgência nas cidades brasileiras para minimizar a notória exclusão dessa parcela social do convívio comunitário. No Brasil segundo dados do Instituto Brasileiro de Geografia e Estatística (IBGE) em 2010, 17,2\% da população possui algum tipo de limitação funcional (físico-motora, cognitiva e sensorial). Desse universo, grande parte não tem acesso e efetiva participação nas diversas atividades sociais, inclusive aquelas que acontecem nos edifícios públicos. Mesmo que haja uma série de leis e normativas que regulamentem a infraestrutura espacial, há um longo caminho a percorrer.

Nesse sentido, acredita-se que a parceria junto ao Observatório Social implica no despertar do assunto pela entidade, que em sua essência representa a sociedade civil. A avaliação realizada no estudo de caso acredita-se promovem inovações "incrementais", preenchendo continuamente o processo de mudança da escola frente a realidade da pessoa com deficiência. Afinal, por se tratar de um projeto de extensão com metodologia participativa há continuamente o envolvimento da comunidade escolar com reflexão acerca do tema e consequente, mudanças locais (escola) e maiores, do entorno escolar e de outros espaços e edifícios públicos.

Por fim, as escolas são responsáveis pela criação e a instrução de comunidades. A partir do momento que é acessível espacialmente, dando aos indivíduos com deficiências as mesmas possibilidades de obter ensino de qualidade, se poderá considerar entre outros, que a sociedade aprenda e conviva com a inclusão em suas diferentes esferas, tornando-se assim, socialmente sustentável.

\section{REFERÊNCIAS}

ABATE, T. P.; KOWALTOWSKI, D. C. C. K.; BERNARDI, N. Questões Éticas na Pesquisa em Avaliação Pós-Ocupação (APO). In: ENCONTRO NACIONAL DE TECNOLOGIA DO AMBIENTE CONSTRUIIDO, 15., Maceió, 2014. Anais... Maceió: ANTAC, 2014.

ABATE, T. P. Instrumentos de Avaliação Pós-Ocupação (APO) Adaptados a PréEscolares Com Deficiência Física, Auditiva e Visual. São Paulo, 2011. Tese 
(Doutorado em Arquitetura e Urbanismo) - Faculdade de Arquitetura e Urbanismo, Universidade de São Paulo, São Paulo, 2011.

ASSOCIAÇÃO BRASILEIRA DE NORMAS TÉCNICAS. Acessibilidade de Pessoas Portadoras de Deficiências a Edificações, Espaço, Mobiliário e Equipamentos Urbanos: NBR 9050. Rio de Janeiro, 2015.

BINS ELY, V. H. M.; BRANDÃO, M. M.; BERTOLETTI, R. Acessibilidade Espacial no Centro Tecnológico da UFSC: avaliação e proposição de soluções projetuais. Florianópolis, 2010.

BRASIL. Censo Escolar da Educação Básica. Brasília, DF, jan. 2017.

. Decreto Federal $n^{\circ}$ 5.296, de 2 de dezembro de 2004. Regulamenta as

Leis $n^{\circ} 10.048$, de 08 de novembro de 2000, que dá prioridade de atendimento às pessoas que especifica, e $n^{\circ} 10.098$, de 19 de dezembro de 2000, que estabelece normas gerais e critérios básicos para a promoção da acessibilidade das pessoas portadoras de deficiência ou com mobilidade reduzida. Diário Oficial da República Federativa do Brasil, Brasília, DF, 2 dez. 2004. Disponivel em: <http://www.planalto.gov.br>. Acesso em: 11 jan. 2019.

DISCHINGER, M.; BINS ELY, V.; PIARDI, S. Promovendo acessibilidade espacial nos edifícios públicos. Florianópolis, SC: MPSC, 2012.

DISCHINGER, M.; ELY, V. H. M. B.; BORGES, M. M. F. C. Manual de Acessibilidade Espacial para Escolas: o direito à escola acessível. Brasília: Ministério da Educação, Secretaria de Educação Especial, 2009.

DISCHINGER, M. Designing for all senses: accessible spaces for visually impaired citizens. Göteborg, Suécia, 2000. - Department of Space and Process, School of Architecture, Chalmers University of Technology.

ROCHA, M. R. M. Crença, mito e verdade. Barcelona, 2002. 103 f. Tese (Doutorado em Educação) - Faculdad de Ciencias de la Educació, Universitat Autónoma de Barcelona, Barcelona, 2002. 